huyết dưới nhện ít cân can thiệp phẫu thuật hơn [3]. Pierre Borczuk và cộng sự (2018), báo cáo 1079 bệnh nhân chấn thương sọ não nhê. Trong số này, 92,4\% được điêuu trị không phẫu thuật và $35,8 \%$ được xuất viện trong vòng 24 giờ sau khi đến điều trị tại đơn vị cấp cứu [4].

\section{KẾT LUÂ̂N}

Chấn thương sọ não nhẹ có tỉ lệ máu tụ nội sọ (64,3\%), đa số điểu trị nội khoa cho kết quả tốt, tuy nhiên diễn biến phức tạp, vẫn có bệnh nhân diên biến nặng để lại di chứng nặng và tử vong.

\section{TÀI LIÊU THAM KHẢO}

1. Đồng Văn Hệ, Kiêuu Đình Hùng (2010), Chẩn đoán và điêuu trị chấn thương sọ não nguy có thấp,
Y học Việt Nam tháng 7- số 1/2010.

2. Pham Ty (2010), Điều tri chấn thương so não nhẹ, Y học Việt Nam tháng 6-số 1/2010.

3. Timothy E Sweeney, và cộng sự (2015), Prediction of neurosurgical intervention after mild traumatic brain injury using the national trauma data bank. World J Emerg Surg. 2015 Jun 6;10:23. doi: 10.1186/s13017-015-0017-6.

4. Pierre Borczuk và cộng sự (2018), Rapid Discharge After Interfacility Transfer for Mild Traumatic Intracranial Hemorrhage: Frequency and Associated Factors. West J Emerg Med. 2019 Mar;20(2):307-315

5. Amir Saied Seddighi và công sự (2013) Factors predicting early deterioration in mild brain trauma: a prospective study. Brain Inj 2013;27(1314):1666-70. doi: 10.3109/02699052.2013.830333.

\title{
ĐÁNH GIÁ MỨC Độ LO ÂU CỦA CÁN Bộ Y TẾ TUYẾN ĐẦU CHỐNG DICH TRONG THỜI GIAN DICH COVID-19 DIỂN BIẾN PHỨC TẠP TẠI ĐÀ NẲNG
}

\author{
Ngô Thị Kim Yến ${ }^{1}$, Trần Thị Hoài Vi ${ }^{1}$, Trần Thanh Thủy ${ }^{1}$, \\ Nguyễn Tiên Hồng ${ }^{1}$, Phạm Thị Kim Chi ${ }^{1}$, Trương Văn Trình ${ }^{1}$,
} Võ Thu Tùng ${ }^{1}$, Nguyễn Ngọc Thanh ${ }^{1}$, Võ Văn Thắng ${ }^{2}$

\section{TÓM TẮT}

Mục tiêu nghiên cứu: Đánh giá mức độ lo âu của các cán bộ $y$ tế tuyến đầu chống dich và mô tả các yếu tố liên quan đến mức độ lo âu của các cán bộ y tế trong thời điểm dịch COVID-19 diễn biến phức tạp tại các cơ sở y tế tuyến đầu chống dịch. Đối tượng và phương pháp nghiên cứu: Cán bộ y tế tại các cơ sở y tế tuyến đầu phòng, chống dịch COVID-19, cụ thể gồm 04 đơn vị: Bệnh viện Đà Nẵng, Bệnh viện Phổi, Trung tâm Y tế huyện Hì̀a Vang (Bệnh viện dã chiến Hoà Vang), Trung tâm Kiểm soát bệnh tật. Tiêu chuẩn chọn đối tượng nghiên cứu: Cán bộ y tế tai các đơn vị tuyến đầu chống dịch COVID-19 tại thời điểm làn sóng dịch thứ 2 tại thành phố Đà Nẵng; Trên 18 tuổi; Không có rối loạn năng lực nhận thức và hành vi; Đồng ý tham gia nghiên cứu. Tiêu chuẩn loại trừ đối tượng nghiên cứu. Không đáp ứng tiêu chuẩn chọn đổi tượng nghiên cứu. Phương pháp nghiên cứu: Nghiên cứu mô tả cắt ngang có phân tích được thực hiện từ tháng 01/2021 đến tháng 05/2021 trển 602 cán bộ y tế đang công tác tại các cơ sở y tế tuyến đầu chống dịch bằng hình thức phỏng vấn trực tiếp đối tượng đích. Bộ cầu hỏi được thiết kế sẵn sử dụng các cẩu hỏi nhiều lựa chọn và sử dụng thang đo DASS21 (lấy ra 07 câu đánh giá về mức độ lo âu).

${ }^{1}$ Sở Y tế thành phố Đà Nẵng

2Viện Nghiên cứu sức khóe cộng động - Trường Đại hoc Y Dướ Huê

Chịu trách nhiệm chính: Trần Thị Hoài Vi

Email: vitth@danang.gov.vn

Ngày nhân bài: 17.5.2021

Ngày phản biên khoa hoc: 8.7.2021

Ngày duyệt bài: 19.7.2021

\begin{tabular}{|c|c|}
\hline Mức độ lo âu & Điếm Lo âu \\
\hline Bình thường & $0-7$ \\
\hline Nhẹ & $8-9$ \\
\hline Vừa & $10-14$ \\
\hline Nặng & $15-19$ \\
\hline Rất nặng & $\geq 20$ \\
\hline
\end{tabular}

Thang đo DASS21 đã được Viên Sức khoẻ tâm thân Quốc gia biên dịch, thử nghiệm trên một số đối tượng nghề nghiệp khác nhau. Thang đo DASS21 đã được nhiều nghiển cứu đánh giá về tính giá trị, độ tin cậy và khẳng đinh có thể áp dụng tai Viêt Nam, không có sư khác biệt về mặt văn hoá. Kểt quả: Trong số 602 đổi tượng tham gia khảo sát, tỷ lệ có biểu hiện rối loạn lo âu ở mức rất cao (70,1\%). Tỷ lệ đối tượng rối loạn lo âu nhe, vừa, năng và rất nặng lần lướt là $6,6 \%, 18,8 \%$ và $44,6 \%$ \% tổng số đối tượng. Tình trạng lo âu hay xảy ra bao gồm: Cảm thây bị khô miệng, hay lo lắng về các tình huống có thể khiến bản thân bẽ mặt, hay bị ra mồ hôi trộm. Có 03 yếu tố dân số và công việc liên quan đến biểu hiện rối loạn lo âu của đối tượng nghiên cứu, trong đó các yếu tố về dân số bao gồm: cơ sở tuyến đâu chống dịch (Biểu hiện lo âu ở Bệnh viện Đà Nẵng cao hơn so với những đổi tượng công tác tại các đơn vị khác $(\mathrm{OR}=3,382 ; 95 \% \mathrm{CI}$ : 1,832-6,243; $p<0,05)$; các yếu tố khác từ công việc liên quan đến biểu hiện lo âu gồm: có tiếp xúc với bệnh nhân COVID$19(\mathrm{OR}=0,361 ; 95 \% \mathrm{CI}: 0,547-1,238 ; \mathrm{p}<0,05)$, tổng điểm áp lực từ nhóm 07 yếu tố áp lực liên quan đến công việc ở mức cao (OR=1,246; 95\%CI: 1,159-1,342; $\mathrm{p}<0,05)$. Kết Iuân: Nghiên cứu chỉ ra trang thái lo âu của các cán bộ tuyến đâu chống dịch bị tắc động nhiêu bởi dich COVID-19 trong thời điểm Đà Nẵng đước xem là tâm dịch COVID-19 của cả nước. Cần có nhiều biện pháp can thiệp để bảo vệ đội ngũ cán bộ y tế trong thời gian đến. 
Tư khóa: COVID-19, mưư độ lo âu, cán bộ y tế tuyến đâuu chống dịch, Đà Nẵng.

\section{SUMMARY \\ ANXIETY LEVEL OF HEALTH WORKERS IN FRONLINE AND DESCRIBE FACTORS RELATED TO THE ANXIETY DURING THE COMPLICATED COVID-19 EPIDEMIC IN DA NANG CITY}

Objective: To evaluate the anxiety level of health workers in fronline and describe factors related to the anxiety during the complicated COVID-19 epidemic in Da Nang city. Subjects and research methods: Health staff at frontline to prevent and control the COVID-19 epidemic, including 04 units: Da Nang Hospital, Lung Hospital, Hoa Vang District Medical Center, Centers for Disease Control. Criteria for selecting research subjects. Health staff at frontline units to prevent and control the COVID-19 epidemic at the time of the second wave of epidemic in Da Nang city; Over 18 years; No cognitive and behavioral disturbances; Agree to participate in the study. Criteria to exclude research subjects. Does not meet the criteria for selecting research subjects. Methods: A descriptive cross-sectional study was conducted from January 01 to May 30, 2021, on 602 health staff in fronline to prevent and control the COVID-19 epidemic in Da Nang city by direct interview. The questionaire use multiple choice questions and use the DASS21 scale (take out 07 questions to assess anxiety levels).

\begin{tabular}{|c|c|}
\hline Level of anxiety & Score \\
\hline Normal & $0-7$ \\
\hline Mild & $8-9$ \\
\hline Medium & $10-14$ \\
\hline Severe & $15-19$ \\
\hline Very severe & $\geq 20$ \\
\hline
\end{tabular}

The DASS21 scale has been compiled by the National Institute of Mental Health and tested on a number of different occupational subjects. The DASS21 scale has been evaluated by many studies for its validity, reliability and affirmation that it can be applied in Vietnam, with no cultural differences. Results: In total 602 respondents completed the questionaire, the rate of anxiety disorders is very high $(70.1 \%)$. The percentages of subjects with mild, moderate, severe and very severe anxiety disorders were $6.6 \%, 18.8 \%$ and $44.6 \%$ of the total subjects, respectively. Common anxiety states include: Feeling dry in your mouth, worrying about situations that might embarrass you, or breaking out in a sweat. There are 03 population and work factors related to the anxiety disorder manifestations of the research subjects, in which the population factors include: frontline anti-epidemic facilities (Anxiety expression in Da Nang Hospital) Nang higher than subjects working in other units $(\mathrm{OR}=3,382 ; 95 \% \mathrm{CI}: 1.832-6.243$; $\mathrm{p}<$ $0.05)$; other factors from work related to anxiety expression include: had contact with a COVID-19 patient $(\mathrm{OR}=0.361 ; 95 \% \mathrm{CI}: 0.547-1.238 ; \mathrm{p}<0.05)$ the total pressure score from the group of 07 workrelated pressure factors was high $(\mathrm{OR}=1.246$; 95\%CI: 1.159-1.342; $p<0.05$. Conclusions: The study showed that status of anxiety disorder of many health workers in fronline were affected by the
COVID-19 epidemic outbreak at Da Nang. There should be many interventions to protect health workers in the coming time.

Keywords. COVID-19, anxiety level, health worker in fronline, Da Nang.

\section{I. ĐẶT VẤN ĐỀ}

Tại thành phố Đà Nẵng, dịch bệnh được ghi nhận qua 02 giai đoạn, trong đó giai đoạn 1 với 06 ca bệnh được phát hiện, điêuu trị khỏi và giai đoạn 2, từ ngày 24/7 đến ngày 23/9 với 389 ca bệnh được phát hiện trong tổng số 657 trường hợp mắc trong nước và 31 trường hợp tử vong trong tổng số 35 ca tử vong trên toàn quốc. [2]

Trong giai đoạn 2, tình hình diễn biến dịch bê̂nh COVID-19 tại Đà Nẵng được đánh giá là hết sức phức tạp với số ca nhiễm COVID-19 mới trong cộng đồng tăng rất cao, số cơ sở y tế bị phong tỏa và cán bộ y tế bị cách ly nhiều; yêu câu kiểm soát dịch là cấp bách. Đà Nẵng được xem là điểm nóng của toàn quốc với số ca nhiếm COVID-19 mới trong cộng đồng tăng rất cao, điều này đã tác động không nhỏ đến người dân thành phố nói chung và ngành y tế nói riêng. Cán bộ y tế tuyến đầu (CBYT) đối mặt với nguy cơ lây nhiễm và tử vong cao hơn đáng kể do phơi nhiễm COVID-19 quá mức [26]. Cũng trong đợt dịch COVID-19 thứ 2 ở Đà Nẵng đã có đến 35 cán bộ y tế dương tính với COVID-19. Sự kết hợp của khối lượng công việc gia tăng, thiếu nhân sự, nguy cơ lây nhiễm chéo và thiếu nguồn lực ảnh hưởng nghiêm trọng đến sức khỏe thể chất và tinh thân của cán bộ y tế và đặt hệ thống chăm sóc sức khỏe dưới gánh nặng cực kỳ nghiêm trọng. [18.]

Nghiên cứu này nhằm mục đích tìm hiểu mức độ lo âu do tác động của đại dịch COVID-19 đến các cán bộ ngành y tế đã và đang công tác tại các cơ sở y tế tuyến đâu phòng chống dịch COVID-19 trên địa bàn thành phố Đà Nẵng, từ đó có định hướng tăng cường các biện pháp bảo vệ đội ngũ cán bộ y tế trong quá trình công tác nói chung và phòng chống dịch bệnh nói riêng trong thời gian đến.

\section{II. ĐỐI TƯợNG VÀ PHƯƠNG PHÁP NGHIÊN CỨU}

+ Đối tượng nghiên cứu: Cán bộ y tế tại các cơ sở y tế tuyến đâu phòng, chống dịch COVID-19, cụ thể gồm 04 đơn vị: Bênh viện Đà Nẵng, Bệnh viện Phổi, Trung tâm $Y$ tể huyện Hòa Vang (Bệnh viện dã chiến Hoà Vang), Trung tâm Kiểm soát bệnh tật.

+ Phương pháp nghiên cứu: Nghiên cứu mô tả cắt ngang có phân tích được thực hiện từ tháng 01/2021 đến tháng 05/2021 trên 602 cán 
bô y tế đang công tác tại các cơ sở y tế tuyến đầu chống dịch bằng hình thức phỏng vấn trực tiếp đối tượng đích. Bộ câu hỏi được thiết kế sẵn sử dụng các câu hỏi nhiều lựa chọn và sử dụng thang đo DASS21 (lấy ra 07 câu đánh giá về mức độ lo âu).

\begin{tabular}{|c|c|}
\hline Câu hỏi & Thang điểm \\
\hline Tôi bị khô miệng & $0 \begin{array}{llll}0 & 1 & 2 & 3\end{array}$ \\
\hline $\begin{array}{c}\text { Tôi bị rối loạn nhịp thở (thở gấp, khó } \\
\text { thở dù chẳng làm việc gì nặng) }\end{array}$ & $\begin{array}{llll}0 & 1 & 2 & 3\end{array}$ \\
\hline $\begin{array}{l}\text { Tôi bị ra mồ hối (chằng hạn như mồ } \\
\text { hôi tay...) }\end{array}$ & $\begin{array}{llll}0 & 1 & 2 & 3\end{array}$ \\
\hline $\begin{array}{l}\text { Tôi lo mình đến những nơi mà tôi có } \\
\text { thể bị hốt hoảng và tự làm mất mặt }\end{array}$ & $\begin{array}{llll}0 & 123\end{array}$ \\
\hline Tôi thấy mình gần như hoảng loạn & $\begin{array}{llll}0 & 1 & 2 & 3\end{array}$ \\
\hline $\begin{array}{l}\text { Tôi nghe thấy rõ tiếng nhịp tim dù } \\
\text { chẳng làm việc gì cả (ví dụ, tiếng } \\
\text { nhịp tim tăng, tiếng tim loạn nhịp) }\end{array}$ & $\begin{array}{llll}0 & 1 & 2 & 3\end{array}$ \\
\hline Tôi hay sợ vô cớ & 01223 \\
\hline $\begin{array}{l}0 \text { - Không đúng với tôi chút nào cả } \\
1 \text { - Đúng với tôi phần, hoặc thỉnh } \\
\text { thoảng mới đúng } \\
2 \text { - Đúng với tôi phần nhiêu, hoặc } \\
\text { phần lớn thời gian là đúng } \\
3 \text { - Hoàn toàn đúng với tôi, hoắc hầu }\end{array}$ & \\
\hline
\end{tabular}

hết thời gian là đúng

Cộng điểm các câu hỏi lại, sau đó nhân 2 và so sánh với bảng kết quả sau.

\begin{tabular}{|c|c|}
\hline Mức độ̣ & Lo âu \\
\hline Bình thường & $0-7$ \\
\hline Nhẹ & $8-9$ \\
\hline Vừa & $10-14$ \\
\hline Nặng & $15-19$ \\
\hline Rắt nặng & $\geq 20$ \\
\hline
\end{tabular}

\section{KẾT QUẢ NGHIÊN CỨU}

\section{1. Đánh giá về mức độ lo âu}

Bảng 3.1. Mức đô đánh giá về múc đô lo âu Sức khỏe tâm thần Số lượng Tỷ lệ (\%) \begin{tabular}{|c|c|c|}
\hline Mức độ lo âu (Anxiety) & 602 & 100,0 \\
\hline
\end{tabular}

Điếm trung bình: 15,2 $\pm 11,048 / 42$

\begin{tabular}{|c|c|c|}
\hline Bình thường & 180 & 29,9 \\
\hline Có biểu hiện, trong đó & 422 & 70,1 \\
\hline Nhẹ & 40 & 6,6 \\
\hline Vừa & 113 & 18,8 \\
\hline Nặng, rất nặng & 269 & 44,6 \\
\hline
\end{tabular}

Nhần xét: Điếm trung bình chung mức độ lo âu là $15,2 \pm 11,048 / 42$. Trong đó, tỷ lệ CBYT có biểu hiện về lo âu trong đợt dịch thứ 2 lần lượt là $70,1 \%$.

Bảng 3.2. Thực trạng lo âu của đôî tượng nghiên cứu theo từng biểu hiện

\begin{tabular}{|c|c|c|c|c|c|c|c|c|}
\hline \multirow[t]{2}{*}{ Mức độ } & \multicolumn{2}{|c|}{$\begin{array}{l}\text { Không } \\
\text { xảy ra }\end{array}$} & \multicolumn{2}{|c|}{$\begin{array}{l}\text { Thinh } \\
\text { thoảng }\end{array}$} & \multicolumn{2}{|c|}{$\begin{array}{c}\text { Thường xảy } \\
\text { ra }\end{array}$} & \multicolumn{2}{|c|}{$\begin{array}{c}\text { Xảy ra thường } \\
\text { xuyên }\end{array}$} \\
\hline & SL & $\%$ & SL & $\%$ & $\mathbf{S L}$ & $\%$ & SL & $\%$ \\
\hline Tôi thấy bi khô miêng & 117 & 19,4 & 139 & 23,1 & 265 & 44,0 & 81 & 13,5 \\
\hline Tôi bi rối loan nhip thở & 235 & 39,0 & 142 & 23,6 & 183 & 30,4 & 42 & 7,0 \\
\hline Tôi bị ra mồ hôi & 147 & 24,4 & 144 & 23,9 & 185 & 30,7 & 126 & 20,9 \\
\hline Lo lắng về các tình huống, mất mặt & 328 & 54,5 & 154 & 25,6 & 99 & 16,4 & 21 & 3,5 \\
\hline Tôi thấy bị hoảng loạn & 267 & 44,4 & 127 & 21,1 & 174 & 28,9 & 34 & 5,6 \\
\hline Tôi nghe rõ nhịp tim mình & 289 & 48,0 & 115 & 19,1 & 166 & 27,6 & 32 & 5,3 \\
\hline Tôi hay sợ vô cớ & 281 & 46,7 & 123 & 20,4 & 168 & 27,9 & 30 & 5,0 \\
\hline
\end{tabular}

Nhân xét: tình trạng lo âu theo từng câu hỏi cụ thể. Tỷ lệ đối tượng cảm thấy bị khô miệng cao nhất là ở mức độ thường xảy ra $(44,0 \%)$. Tỷ lệ đối tượng cảm thấy lo lắng về các tình huống có thể khiến họ bẽ mặt/xấu hổ theo các mức độ lần lượt là: 25,6\% (thỉnh thoảng); 16,4\% (thường xảy $\mathrm{ra}$ ); $3,5 \%$ (xảy ra thường xuyên). Tỷ lệ đối tượng hay bị ra mồ hôi theo các mức độ lần lượt là: $23,9 \%$ (thỉnh thoảng); $30,7 \%$ (thường xảy ra); 20,9\% (xảy ra thường xuyên). Tỷ lệ đối tượng cảm thấy có thể nghe rõ nhịp tim mình dù không có việc gì theo các mức độ lần lượt là: 19,1\% (thỉnh thoảng); 27,6 (thường xảy ra); $5,38 \%$ (xảy ra thường xuyên). Tỷ lệ đối tượng hay sợ hãi vô cớ theo các mức độ lần lượt là: $20,4 \%$ (thỉnh thoảng); $27,9 \%$ (thường xảy ra); $5,0 \%$ (xảy ra thường xuyên).

Biểu đồ 3.3. Thực trạng lo âu của đôi tương nghiên cứu theo nhóm yếu tố

\begin{tabular}{|c|c|c|c|c|c|c|}
\hline \multirow{2}{*}{$\begin{array}{c}\text { Yếu tố/nhóm yếu } \\
\text { tố }\end{array}$} & \multirow{2}{*}{ Giá trị } & \multicolumn{4}{|c|}{ Lo âu } & \multirow{2}{*}{ Tổng } \\
\cline { 3 - 6 } & & \multicolumn{3}{|c|}{ Bình thường } & Có biếu hiên & \\
\cline { 3 - 6 } & CDC & 25 & 51,0 & 24 & 49,0 & $\mathbf{n}$ \\
\hline \multirow{3}{*}{ Đơn vị } & Bệnh viện Phối & 25 & 34,2 & 48 & 65,8 & 73 \\
\hline & TTYYT Hoà Vang & 49 & 36,0 & 87 & 64,0 & 136 \\
\cline { 2 - 7 } & BV Đà Năng & 81 & 23,5 & 263 & 76,5 & 344 \\
\hline
\end{tabular}




\begin{tabular}{|c|c|c|c|c|c|c|}
\hline \multirow{2}{*}{ Giới tính } & Nam & 72 & 34,8 & 135 & 65,2 & 207 \\
\hline & Nữ & 108 & 27,3 & 287 & 72,7 & 395 \\
\hline \multirow{2}{*}{$\begin{array}{c}\text { Có tiếp xúc với } \\
\text { COVID-19 }\end{array}$} & Có & 103 & 23,8 & 329 & 76,2 & 432 \\
\hline & Không & 77 & 45,3 & 93 & 54,7 & 170 \\
\hline \multirow{7}{*}{$\begin{array}{l}\text { Chức danh chuyên } \\
\text { môn }\end{array}$} & Bác sỹ & 44 & 40,0 & 66 & 60,0 & 110 \\
\hline & Điều dưỡng & 66 & 22,3 & 230 & 77,7 & 296 \\
\hline & Xét nghiệm & 23 & 32,4 & 48 & 67,6 & 71 \\
\hline & Kỹ thuật viên & 04 & 22,2 & 14 & 77,8 & 18 \\
\hline & Hành chính & 23 & 62,2 & 14 & 37,8 & 37 \\
\hline & Hộ lý, vệ sinh & 09 & 20,9 & 34 & 79,1 & 43 \\
\hline & Khác & 11 & 40,7 & 16 & 59,3 & 27 \\
\hline \multicolumn{2}{|c|}{ Tống công } & 180 & 29,9 & 422 & 70,1 & 602 \\
\hline
\end{tabular}

Nhận xét: số lượng đội tượng nghiên cứu có hiện tượng lo âu ở các đơn vị tuyến đầu chống dịch lần lượt là 76,5\% (Bệnh viện Đà Nẵng); Bệnh viện Phổi $(65,8 \%) ; 64,0 \%$ (TTYT Hòa Vang); TTKSBT $(49,0 \%)$; số đối tượng có hiện tượng lo ẩu ở nữ nhiêu hơn ở nam với tỷ lệ lần lượt là $72,7 \%$ và 65,2\%; số đối tượng có hiện tượng lo âu ở nhóm tiếp xúc bệnh nhân COVID-19 hơn ở nhóm không tiếp xúc với tỷ lệ lần lượt là $76,2 \%$ và $54,7 \%$.

\subsection{Các yếu tố liên quan:}

Bảng 3.4. Có mối liên quan thực sự đến biểu hiện lo âu bằng phân tích hồi quy

\begin{tabular}{|c|c|c|c|}
\hline Yếu tố liền quan & OR & $95 \% \mathrm{CI}$ & $\mathbf{p}$ \\
\hline 1.Giới (Tham chiếu: Nam) & 1,147 & $0,774-1,699$ & $p=0,495>0,05$ \\
\hline 2.Trình độ học vấn (Tham chiếu: Trung cấp, cao đằng) & 0,843 & $0,655-1,086$ & $\mathrm{p}=0,187>0,05$ \\
\hline 3.Chức danh chuyên môn (Tham chiếu: Bác sỹ) & 1,011 & $0,899-1,135$ & $p=0,859>0,05$ \\
\hline Đơn vị công tác (Tham chiếu: CDC) & & & $p=0,000<0,05$ \\
\hline -Bệnh viện Đà Nẵng & 3,382 & $1,832-6,243$ & $p=0,00<0,05$ \\
\hline -Bệnh viện Phổi & 1,829 & $1,190-2,810$ & $p=0,040<0,05$ \\
\hline -TTYYT Hòa Vang & 1,691 & $0,982-1,913$ & $p=0,058>0,05$ \\
\hline 5.Loại hình lao động (Tham chiếu: Biên chế) & 1,029 & $0,695-1,523$ & $\mathrm{p}=0,888>0,05$ \\
\hline $\begin{array}{l}\text { Có tiếp xúc với bệnh nhần mắc COVID- } 19 \text { (Tham } \\
\text { chiếu: Cón tiếp xúc) }\end{array}$ & 0,361 & $0,547-1,238$ & $p=0,000<0,05$ \\
\hline 7.Khối lượng công việc quá tải (Tham chiếu: Có quá tải) & 1,164 & $0,703-1,928$ & $p=0,555>0,05$ \\
\hline 8.Thời gian làm việc quá 8 giờ (Tham chiếu: quá 8 giờ) & 1,088 & $0,669-1,771$ & $p=0,733>0,05$ \\
\hline $\begin{array}{l}\text { 9.Tống áp lực (tống điếm tứ 7-21; tham chiếu từ điếm } \\
\text { số thấp nhất) }\end{array}$ & 1,246 & $1,159-1,342$ & $p=0,000<0,05$ \\
\hline
\end{tabular}

Nhận xét: Kễt quả phân tích hồi quy đa biến ghi nhận, có 03 yếu tố có mối liên quan thực sự đến mức độ lo âu ở CBYT trong đợt dịch thứ 2, gồm: Đơn vị công tác; Có tiếp xúc với bệnh nhân COVID19; Tổng áp lực gặp phải. Xu hướng tăng giảm mức độ lo âu ở các nhóm này tương tự như phần phân tích ở mức độ trầm cảm.

\section{BÀN LUÂN}

Những đối tượng nghiên cứu công tác tại các cơ sở tuyến đầu chống dịch có nguy cơ rối loạn lo âu có xu hướng tăng dần từ thấp đến cao, với thấp nhất là Trung tâm Kiểm soát bệnh tât thành phô̂ và cao nhất là CBYT thuộc Bệnh viện Đà Nẵng.

Vị trí đơn vị công tác là một trong những yểu tố có liên quan mật thiết đến sức khỏe tâm thần của các cán bộ y tế, điều này cũng được ghi nhận tại một cuộc khảo sát năm 2020 tại Việt Nam và cũng sử dụng thang điểm DASS-21, trong tổng số 173 CBYT được tham gia vào nghiên cứu, tần suất của các triệu chứng lo âu là $33,5 \%$. Tỷ lệ về các vấn đề sức khỏe tâm thần của CBYT theo chỉ định bênh viện cao hơn đáng kể so với CBYT từ bệnh viện không chỉ định [3].
Tương tự với nghiên cứu tại Bangladesh, cũng cho rẳng $\mathrm{CBYT}$ đang trải qua khối lượng công việc nặng nề là yếu tố góp phần làm tăng lo âu ở CBYT ngoài ra ở nghiên cứu này còn cho rằng thiếu $\mathrm{PPE}$, nhiều yếu tố khác cũng góp phần làm tăng lo lắng trong đại dịch COVID-19.

Có 02 yếu tố công việc có liên quan đên tình trạng lo âu của đối tượng nghiên cứu bao gồm: có tiếp xúc với bệnh nhân mắc COVID-19 và tổng điểm áp lực gặp phải của CBYT.

Đây cũng là những yếu tố áp lực gây ảnh hưởng đến tình trạng lo âu mà nhiều nghiên cứu khác đã đề cập [8]. Nghiên cứu cho thấy áp lực từ thời gian làm việc và khối lượng công việc vẩn là những yếu tố hàng đầu ảnh hưởng đến tình trạng trầm cảm của đối tượng nghiên cứu. 
Ngoài ra, cũng tương tự như ghi nhận từ nghiên cứu của tác giả Nguyễn Thị Phương Lan và cộng sự đã ghi nhận rằng đa số $(73,9 \%)$ lo ngai về việc xét nghiệm dương tính với COVID19 và lây nhiễm cho gia đình của họ [7].

\section{KẾT LUẬN}

Nhận thấy tỷ lệ bị tác động của dịch COVID19 đến các cán bộ y tế là khá cao, do vậy rất cần thiết xây dựng kế hoạch nâng cao biện pháp bảo vệ cán bộ y tế trong các vụ dịch nói riêng và các sự kiện thảm họa y tế nói chúng.

\section{TÀI LIÊU THAM KHẢO}

1. Bộ Y tế (2020), Sáng $16 / 10$ không ca mắc CÖVID-19, Viêtt Nam chữa khỏi 1.030 bênh nhân, https://ncov.moh.gov.vn/vi/web/guest/-/6847426-335.

2. Holshue $M L$, DeBolt $C$, Lindquist $S$, Lofy $\mathbf{K H}$, Wiesman J, Bruce H, et al. First case of 2019 novel coronavirus in the United States. N Engl J Med. 2020;382(10):929-36. https:// doi.org/ 10.1056/ NEJMoa2001191.

3. Dimitrios Giannis (2020), Impact of coronavirus disease 2019 on healthcare workers: beyond the risk of exposure, Postgraduate Medical Journal.

4. Thân Mạnh Hùng và cộng sự (2020), "Sức khỏe Tâm thân và Kết quả Chất lượng Cuộc sống Liên quan đến Sức khỏe của các Nhân viên $Y$ tế Tuyến đâuu trong Thời kỳ Đỉnh điểm bùng phát COVID-19 ở Việt Nam: Một nghiên cứu cắt ngang". Risk Management And Healthcare Polyci 2020; 13:2927-2936.

5. Rafia Tasnim, Md. Saiful Islam (2020), "Prevalence and correlates of anxiety and depression in frontline healthcare workers treating people with COVID-19 in Bangladesh". PsyArXiv, 23 Sept. 2020, pp. 4,5,10.

6. Ngọc Sao (2017), Thực trạng sức khỏe tâm thần và một số yếu tố liên quan của nhân viên khoa Hồ sức cấp cứu tai một số bênh viện trên đia bàn Hà Nội năm 2017.

7. Nguyễn Thị Phương Lan và cộng sự, "Các yếu tố căng thẳng tâm lý,mối quan tầm và hỗ trợ sức khỏe tấm thần cho nhân viên chăm sóc sức khỏe ở Việt Nam trong thời gian bùng phát dịch bệnh Coronavirus 2019 (Covid 19)". Public Health, 19 March 2021, pp. 2. https: //doi.org/ 10.3389/fpubh.2021.628341.

\title{
ĐĂC ĐIỂM LÂM SÀNG, NộI SOI, MÔ BÊ̂NH HỌC VÀ TỶ LÊ NHIỄM HELICOBACTER PYLORI Ở BÊ̂NH NHÂN UNG THƯ DẠ DÀY
}

\author{
Phạm Hồng Khánh ${ }^{2}$, Trần Thị Huyền Trang ${ }^{1}$, \\ Nguyễn Quang Duật ${ }^{2}$, Vũ Văn Khiênn ${ }^{1}$
}

\section{TÓM TẮT}

Đặt vấn đê: Ung thư dạ dày vẫn là căn bệnh ung thư quan trọng trên toàn thế giới và là nguyển nhân gây ra hơn một triệu ca mắc mới vào năm 2020 và ước tính có khoảng 769.000 ca tử vong, đứng thứ 5 về tỷ lệ mắc và thứ 4 về tỷ lệ tử vong trên toàn câu. Mục tiểu: Nghiên cứu về đặc điểm lâm sàng, nội soi, mô bệnh học và nhiếm $\mathrm{H}$. pylori ở bệnh nhân UTDD. Đối tương \& phương pháp: 129 bệnh nhân UTDD được chẩn đoán xác định trên nội soi và mô bệnh học. Hình ảnh đại thể UTDD dựa trên phân loại cửa Borrman. Phẩn loai mô bênh học theo Lauren. Chẩn đoán nhiễm $\mathrm{H}$. pylori dựa trên: CLO test, mô bệnh hoc và nuôi cây. Kết quả: Đăc điểm chung: Tuổi $\geqq 60$ tuổi $(67,7 \%)$, tuổi trung bình: 63,8 111,9 (29-92). Lâm sàng: Đau thượng vi $(97,7 \%)$, đây bung $(88,4 \%)$, chán ăn $(82,2 \%)$, gây sút cân $(39,5 \%)$. Vị trí khối u: Hang vị $(48,1 \%)$, thân vị $(17 \%)$, tâm vị $(6,2 \%)$. Mô bệnh học: Thể ruột $(55,4 \%)$, thể lan tỏa $(40,8 \%)$ và hốn hợp $(3,8 \%)$. Tỷ lệ nhiếm $H$. pylori ở bệnh nhân

${ }^{1}$ Bệnh viện TWQD 108

²Bệnh viện 103- Học viện Quân y

Chịu trách nhiệm chính: Vũ Văn Khiên

Email: vuvankhien108@yahoo.com.vn

Ngày nhận bài: 17.5.2021

Ngày phản biên khoa học: 5.7.2021

Ngày duyệt bài: 19.7.2021
UTDD là: 77/129 (59,2\%). Kết luận: Tỷ lệ nhiễm H. pylori ở bệnh nhân UTDD chiếm 59,2\%.

Tư khóa: Ung thư da dày, Helicobacter pylori

\section{SUMMARY}

CHARACTERISTICS OF CLINICAL ENDOSCOPIC, HISTOPATHOLOGIC AND HELICOBACTER PYLORI INFECTION IN PATIENTS WITH GASTRIC CANCER

Introduction: Stomach cancer remains an important cancer worldwide and is responsible for over one million new cases in 2020 and an estimated 769.000 deaths, ranking fifth for incidence and fourth for mortality globally. Objectives: To study the clinical, endoscopic, histopathological and $\mathrm{H}$. pylori characteristics in patients with gastric cancer. Patient \& methds: 129 patients with gastric cancer were confirmed on endoscopy and histopathology. Clinicopathological features based on Borrmann's classification. Histopathological features based on Lauren's classification. Diagnosis of $\mathrm{H}$. pylori infection is based on: CLO test, histopathology and culture. Results: General characteristics: Age $\geqq 60$ years old $(67.7 \%)$, mean age: $63.8 \pm 11.9$ (29-92). Clinical: Epigastric pain $(97.7 \%)$, bloating $(88.4 \%)$, anorexia $(82.2 \%)$, weight loss (39.5\%). Tumor location: antrum $(48.1 \%)$, body $(17 \%)$, cardia (6.2\%). Histopathology: Intestinal type (55.4\%), diffuse type $(40.8 \%)$ and mixed $(3.8 \%)$. The rate of $H$. pylori 